\title{
Atividade proteolítica de isolados de Metarhizium anisopliae sobre substratos cuticulares e não-cuticulares
}

\author{
Proteolytic activity of Metarhizium anisopliae isolates on cuticular and noncuticular substrates
}

\author{
Patrícia Vieira Tiago $^{*}$ Ricardo José da Silva $^{\mathrm{I}}$
}

\section{RESUMO}

Cigarrinhas são as principais pragas da pastagem e da cana-de-açúcar, destacando-se os gêneros Deois $e$ Mahanarva. Essas pragas vêm causando sérios danos a estas culturas na região de Tangará da Serra, MT, Brasil. O fungo Metarhizium anisopliae é considerado um eficiente agente para o controle biológico de insetos, possuindo vários fatores de virulência, incluindo a produção de proteases, consideradas fundamentais no processo de penetração através da cutícula do inseto. Este trabalho tem como objetivos analisar a produção de proteases extracelulares a partir de isolados de $\boldsymbol{M}$. anisopliae, utilizando substratos cuticulares e não-cuticulares, e verificar a influência desses substratos na expressão dessas enzimas. Foram utilizados 4 isolados de M. anisopliae obtidos na região de Tangará da Serra e o isolado $R 3$ BB 40, empregado para o controle biológico das cigarrinhas da canade-açúcar pelas Usinas Itamarati (Nova Olímpia / MT). A atividade enzimática foi determinada através do Índice de Relação Enzimática (IRE) em Meio Mínimo (MM), sem glicose, acrescido de caseína, gelatina e cutícula de adultos de Mahanarva fimbriolata e Deois flavopicta. Os isolados UNEMAT 03, UNEMAT 04, UNEMAT 05, UNEMAT 06 e R3$B B-40$ apresentaram valores de IRE que variaram de 1,82 \pm 0,062 a 2,16 $\pm 0,027$ frente ao substrato gelatina e de 1,60 \pm 0,076 a 2,08 $\pm 0,063$ em caseína. Para os substratos cuticulares, houve crescimento das colônias, porém não apresentaram revelação de halo $(I R E .=1)$. Todos os isolados apresentaram IRE frente ao substrato gelatina $>$ caseína $>$ cutícula, destacandose os isolados R3-BB-40 e UNEMAT 05. Existe uma variabilidade genética entre os isolados quanto à produção de proteases extracelulares $e$, sob tais condições, as cutículas não demonstraram ser substrato adequado para a detecção de atividade proteolítica.

Palavras-chave: fungos entomopatogênicos, proteases, Mahanarva fimbriolata, Deois flavopicta.

\begin{abstract}
Froghoppers are the main pests of pasture and sugarcane, among which the genera Deois and Mahanarva stand out. These pests have been causing serious losses in the cultures of the region of Tangará da Serra, state of Mato Grosso, Brazil. The fungus Metarhizium anisopliae is considered an efficient agent for the biological control of insects, possessing various factors of virulence, including the production of proteases considered essential in the process of penetration through the insect's cuticle. The purpose of this work is to analyze the production of extracellular proteases from isolates of M. anisopliae, using cuticular and noncuticular substrates to ascertain their influence on the expression of these enzymes. Four M. anisopliae isolates collected in the region of Tangará and the isolate R3 BB 40 used for the biological control of froghoppers in the sugarcane plantations of the Itamarati sugar mills (Nova Olimpia, MT, Brazil) were used. The enzymatic activity was determined from the Enzyme Relation Index (ERI) in Minimum Medium (MM) without glucose, with the addition of casein, gelatin and cuticle from adult Mahanarva fimbriolata and Deois flavopicta. The UNEMAT 03, UNEMAT 04, UNEMAT 05, UNEMAT 06 and R3-BB-40 isolates presented ERI values varying from $1.82 \pm 0.062$ to $2.16 \pm 0.027$ with gelatin substrate and from $1.60 \pm 0.076$ to $2.08 \pm 0.063$ with casein. The cuticular substrates showed colony growth, but revealed no halo (ERI = 1). All the isolates presented ERI with gelatin $>$ casein $>$ cuticle substrate, with the highest values going to the R3-BB-40 and UNEMAT 05 isolates. Isolates display natural variability in terms of extracellular protease production and under these conditions the cuticles proved to be an inadequate substrate for the detection of proteolytic activity.
\end{abstract}

Key words: entomopathogenic fungi, proteases, Mahanarva fimbriolata, Deois flavopicta.

${ }^{1}$ Departamento de Ciências Biológicas, Universidade do Estado de Mato Grosso (UNEMAT), Campus Universitário de Tangará da Serra, Rod. MT 358, Km 07, CP 287, 78300-000, Tangará da Serra, MT, Brasil. E-mail: patiago@unemat.br. *Autor para correspondência. 


\section{INTRODUÇÃO}

Cigarrinhas (Hemiptera: Cercopidae) se destacam como as principais pragas de gramíneas forrageiras e da cana-de-açúcar, causando redução do crescimento e da capacidade de suporte das pastagens e prejuízos no rendimento agrícola e industrial na cultura de cana-de-açúcar (ALMEIDA et al., 2000). Na região de Tangará da Serra (MT), tem sido verificado alto índice de infestação de Mahanarva fimbriolata e Deois flavopicta em áreas de pastagens e de cana-de-açúcar (PEREIRA et al., 2004; SILVA et al., 2004).

Inseticidas químicos são normalmente empregados para o combate das cigarrinhas, porém não são eficientes devido à localização das ninfas desses insetos no solo (LEITE et al., 2002). O fungo entomopatogênico Metarhizium anisopliae tem sido utilizado no controle biológico de cigarrinhas que atacam pastagens e cana-de-açúcar, sendo este um dos programas mais antigos, no qual foram realizados estudos de coleta e seleção de isolados com diferentes graus de virulência, de especificidade para cada praga visada e de adaptação a condições ambientais diversas. $\mathrm{O}$ uso deste fungo tem demonstrado eficiência que variou de 30 a $80 \%$ no controle das cigarrinhas da canade-açúcar e de 10 a 60\% no controle das cigarrinhas das pastagens (ALVES, 1998).

Os fungos entomopatogênicos penetram no hospedeiro via tegumento, o que os coloca em vantagem quando comparados com outros grupos de patógenos que só entram no inseto por via oral. Evidências obtidas por microscopia eletrônica e histoquímica sugerem que a etapa de penetração ocorre por uma combinação de degradação enzimática e pressão mecânica (St. LEGER et al., 1988). As enzimas proteolíticas ou proteases, além de estarem envolvidas nos processos de formação e germinação dos conídios, têm funções nutricionais importantes, sendo capazes de hidrolisar as cadeias polipeptídicas em cadeias menores, que são absorvidas pelas células.

A produção de proteases tem sido estudada com várias finalidades, como a de correlacioná-las com os processos de especificidade, patogenicidade e virulência. Assim, diversos estudos associados à produção de proteases por $\boldsymbol{M}$. anisopliae demonstram uma grande variabilidade genética entre os isolados, quando cultivados em meios de cultura contendo diferentes fontes de carbono e nitrogênio, não existindo relatos a respeito de atividade proteolítica frente às cutículas das cigarrinhas $\boldsymbol{M}$. fimbriolata e $\boldsymbol{D}$. flavopicta.

Os objetivos deste trabalho foram analisar a produção de proteases extracelulares a partir de isolados de $\boldsymbol{M}$. anisopliae, obtidos na região de Tangará da Serra (MT), utilizando substratos cuticulares e não-cuticulares, e verificar a influência desses substratos na expressão dessas enzimas.

\section{MATERIAL E MÉTODOS}

Foram utilizados quatro isolados de $\boldsymbol{M}$. anisopliae, obtidos a partir de cigarrinhas $\boldsymbol{M}$. fimbriolata coletadas na região de Tangará da Serra, MT, e o isolado R3- BB-40, que é empregado para controle biológico das cigarrinhas da cana-de-açúcar pelas Usinas Itamarati (Nova Olímpia / MT).

Realizou-se a análise da produção semiquantitativa de proteases extracelulares dos isolados UNEMAT 03, UNEMAT 04, UNEMAT 05, UNEMAT 06 e R3-BB-40 do fungo entomopatogênico M. anisopliae após cultivo em Meio Mínimo (MM) (PONTECORVO et al., 1953) sem glicose, acrescido de diferentes fontes de nitrogênio (gelatina, caseína e cutícula de adultos de $\boldsymbol{D}$. flavopicta e $\boldsymbol{M}$. fimbriolata).

Para o preparo da solução de caseína (1\%), dissolveu-se caseína não-hidrolisada em $\mathrm{NaOH}(0,05 \mathrm{M})$ e, após completa dissolução, ajustou-se o pH para 6,0 e completou-se o volume final com água destilada. A solução foi mantida em vapor úmido a $121^{\circ} \mathrm{C}$ por 20 minutos. Realizou-se o mesmo procedimento para a preparação da solução de gelatina (1\%). Para a obtenção de cutículas, foram utilizados adultos de $\boldsymbol{D}$. flavopicta e $\boldsymbol{M}$. fimbriolata coletados em pastagens e em plantios comerciais de cana-de-açúcar no município de Tangará da Serra, MT. Os insetos foram secados em estufa a $80^{\circ} \mathrm{C}$, dissecados, e o exoesqueleto foi macerado. O pó resultante foi peneirado e armazenado separadamente em freezer a $-20^{\circ} \mathrm{C}$. Para obtenção de solução de cutícula (1\%), esta foi ressuspendida em uma solução de tetraborato de potássio (1\%) e submetida a vapor fluente por 20 minutos (ANDERSEN, 1980). Posteriormente, os substratos cuticulares e nãocuticulares foram adicionados ao MM previamente esterilizado.

Para a análise da produção semiquantitativa de proteases, com o auxílio de uma câmara de Neubauer, obteve-se uma suspensão de conídios de $1 \times 10^{8} \mathrm{con} /$ $\mathrm{mL}$, sendo $0,01 \mathrm{~mL}$ desta suspensão inoculada em um disco de papel filtro estéril de $6 \mathrm{~mm}$. Este posteriormente foi transferido para placa de Petri $(9 \times 1,5 \mathrm{~cm})$ contendo MM acrescido de substrato (caseína, gelatina e cutícula de $\boldsymbol{D}$. flavopicta e $\boldsymbol{M}$. fimbriolata). Os isolados foram incubados em câmara climatizada tipo BOD por 10 dias a $26^{\circ} \mathrm{C}$ e fotoperíodo de 12 horas.

Após o período de incubação, adicionouse nas placas solução de ácido tricloroacético $10 \%$ 
(TCA) para revelação dos halos de degradação. A atividade proteolítica foi determinada pelo Índice de Relação Enzimática (IRE = D/d), em que D = diâmetro total (colônia + halo) e d = diâmetro da colônia.

O experimento foi realizado através de delineamento inteiramente casualizado, com vinte tratamentos e seis repetições. Os tratamentos foram representados pelos isolados UNEMAT 03, UNEMAT 04, UNEMAT 05, UNEMAT 06 e $\mathrm{R}_{3}$-BB-40 de $\boldsymbol{M}$. anisopliae e pelos substratos gelatina, caseína e cutícula de adultos de $\boldsymbol{D}$. flavopicta e $\boldsymbol{M}$. fimbriolata. Os dados foram submetidos à análise de variância a 5\% de probabilidade, e as médias comparadas pelo teste de Tukey com o “software” SAEG 8.0 (2001).

\section{RESULTADOS E DISCUSSÃO}

A atividade proteolítica do isolado R3-BB40 apresentou maior índice de relação enzimática (IRE $=2,16 \pm 0,027$ ) em MM acrescido de gelatina que os isolados obtidos de $\boldsymbol{M}$. fimbriolata com 1,88 \pm 0,019; $1,82 \pm 0,062 ; 1,96 \pm 0,096$ e 1,92 $\pm 0,150$, respectivamente (Figura 1). Variabilidade genética também foi observada para o fungo entomopatogênico Beauveria bassiana cultivado em MM acrescido de gelatina, com única fonte de nitrogênio (PACCOLA-MEIRELLES \& AZEVEDO, 1990).

Quanto à atividade proteolítica dos diferentes isolados de $\boldsymbol{M}$. anisopliae frente ao MM acrescido de caseína, constatou-se que o isolado R3BB-40 apresentou maior IRE $(2,08 \pm 0,063)$, seguido pelos isolados UNEMAT 05 e UNEMAT 06, que foram semelhantes entre si (1,91 $\pm 0,138$ e 1,80 \pm 0,10); porém, estes diferiram dos isolados UNEMAT 03 e UNEMAT 04 , que apresentaram os menores IREs $(1,60 \pm 0,076 \mathrm{e}$ 1,64 \pm 0,041), sendo estes semelhantes (Figura 1). Variabilidade genética na produção de proteases extracelulares foi verificada para isolados de $\boldsymbol{M}$. anisopliae quando cultivados em meio completo contendo caseína como fonte de nitrogênio (ROSATO et al., 1981). Tal variabilidade também foi constatada em ensaios enzimáticos com diferentes isolados de $\boldsymbol{M}$. anisopliae em meio líquido, contendo caseína como única fonte de nitrogênio (BRAGA et al., 1999; PINTO et al., 2002).

Estes resultados demonstram a ocorrência de variabilidade genética entre os isolados quanto à produção de proteases extracelulares. O isolado R3BB-40 apresentou os maiores valores de IRE, tanto em meio contendo gelatina quanto caseína, ressaltandose também os isolados UNEMAT 05 e UNEMAT 06, que são iguais aos isolados UNEMAT 03 e UNEMAT 04 na gelatina; porém, estes últimos apresentaram os menores valores de IRE em caseína. Alguns autores verificaram que isolados de $M$. anisopliae, em ensaios enzimáticos em placa, produzem maior quantidade de proteases em MM acrescido de caseína do que em MM acrescido de gelatina (SPACKI et al., 2001).

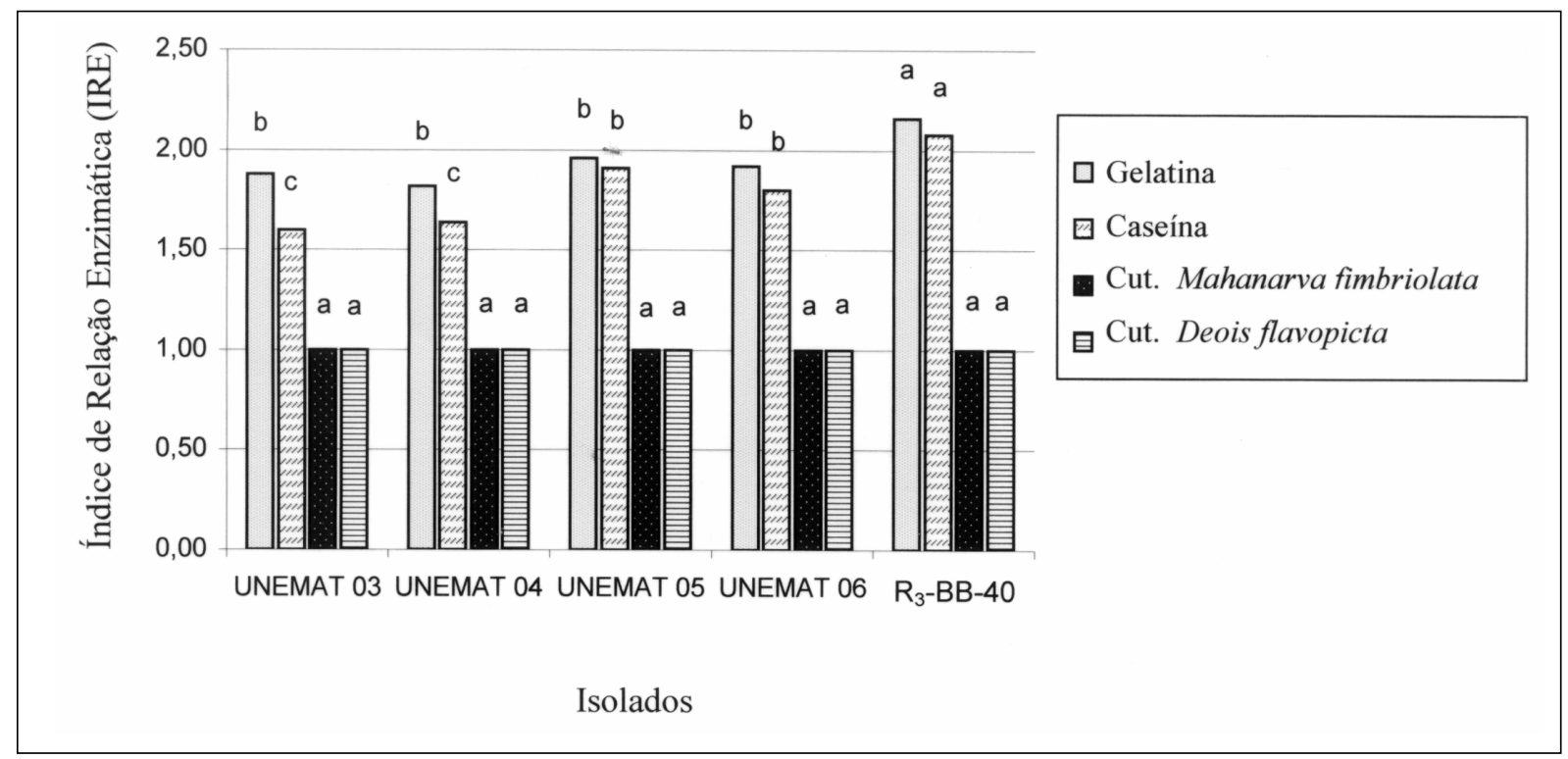

Figura 1 - Atividade proteolítica de isolados de Metarhizium anisopliae após incubação em Meio Mínimo (MM) acrescido de caseína, gelatina e cutícula de cigarrinha, como fonte de nitrogênio. Médias seguidas de letras iguais não diferem significativamente entre si pelo teste de Tukey a $5 \%$ de probabilidade.

Ciência Rural, v.37, n.1, jan-fev, 2007. 
Quanto à atividade proteolítica dos diferentes isolados de $\boldsymbol{M}$. anisopliae frente ao MM acrescido de cutícula de $\boldsymbol{D}$. flavopicta e $\boldsymbol{M}$. fimbriolata, constatou-se, para todos os isolados testados e para os dois substratos cuticulares, ausência de halo de degradação (IRE = 01). Os resultados obtidos sugerem que, sob as condições testadas, as cutículas de $\boldsymbol{M}$. fimbriolata e $\boldsymbol{D}$. flavopicta não demonstraram ser substrato adequado para a detecção de atividade proteolítica em placa (Figura 1). Proteases extracelulares (Pr1 e Pr2) têm sido produzidas por isolados de $\boldsymbol{M}$. anisopliae quando cultivados em meios líquidos contendo cutículas de diversos insetos, como as dos gafanhotos Schistocerca pallens, Rhammatocerus schistocercoides e Schistocerca gregaria e as da mariposa Manduca sexta (TIAGO et al., 2002; PINTO et al., 2002; PATERSON et al., 1994 e ST. LEGER et al., 1988).

Quanto à influência dos substratos na atividade proteolítica dos isolados de $\boldsymbol{M}$. anisopliae, verificou-se, para os isolados R3-BB-40, UNEMAT 05 e UNEMAT 06, que tanto caseína quanto gelatina influenciaram positivamente na expressão das proteases, não havendo diferenças entre estes substratos. No entanto, para os isolados UNEMAT 03 e UNEMAT 04, foram observadas diferenças quanto à influência dos substratos caseína e gelatina na expressão das proteases, sendo que este último demonstrou ser o melhor substrato. Já para os substratos cuticulares foi observada uma menor influência na expressão das proteases para todos os isolados estudados, quando comparados aos substratos não-cuticulares (caseína e gelatina) (Figura 2).

Os resultados obtidos para produção de proteases extracelulares demonstraram a ocorrência de variabilidade genética entre os isolados, permitindo uma avaliação preliminar da quantidade de proteases secretadas por estes isolados. Os isolados UNEMAT 05, UNEMAT 06 e $\mathrm{R}_{3}$-BB-40 poderão ser, posteriormente, analisados quanto à produção de proteases específicas, como Pr1 e Pr2, e estudos como este possibilitarão uma melhor compreensão dos possíveis fatores que poderão afetar a eficiência destes isolados no controle de determinados insetos-praga. Tais informações, juntamente com a análise de virulência, servirão de base para a seleção de isolados de $M$. anisopliae a serem produzidos em escala massal.

\section{CONCLUSÕES}

Existe variabilidade genética entre os isolados para produção de proteases extracelulares frente aos substratos não-cuticulares. Os substratos cuticulares testados não são adequados para a detecção de atividade proteolítica em placa.

\section{AGRADECIMENTOS}

À Pró-Reitoria de Pesquisa e Pós-Graduação da Universidade do Estado de Mato Grosso, pelo auxílio financeiro que possibilitou a realização deste trabalho.

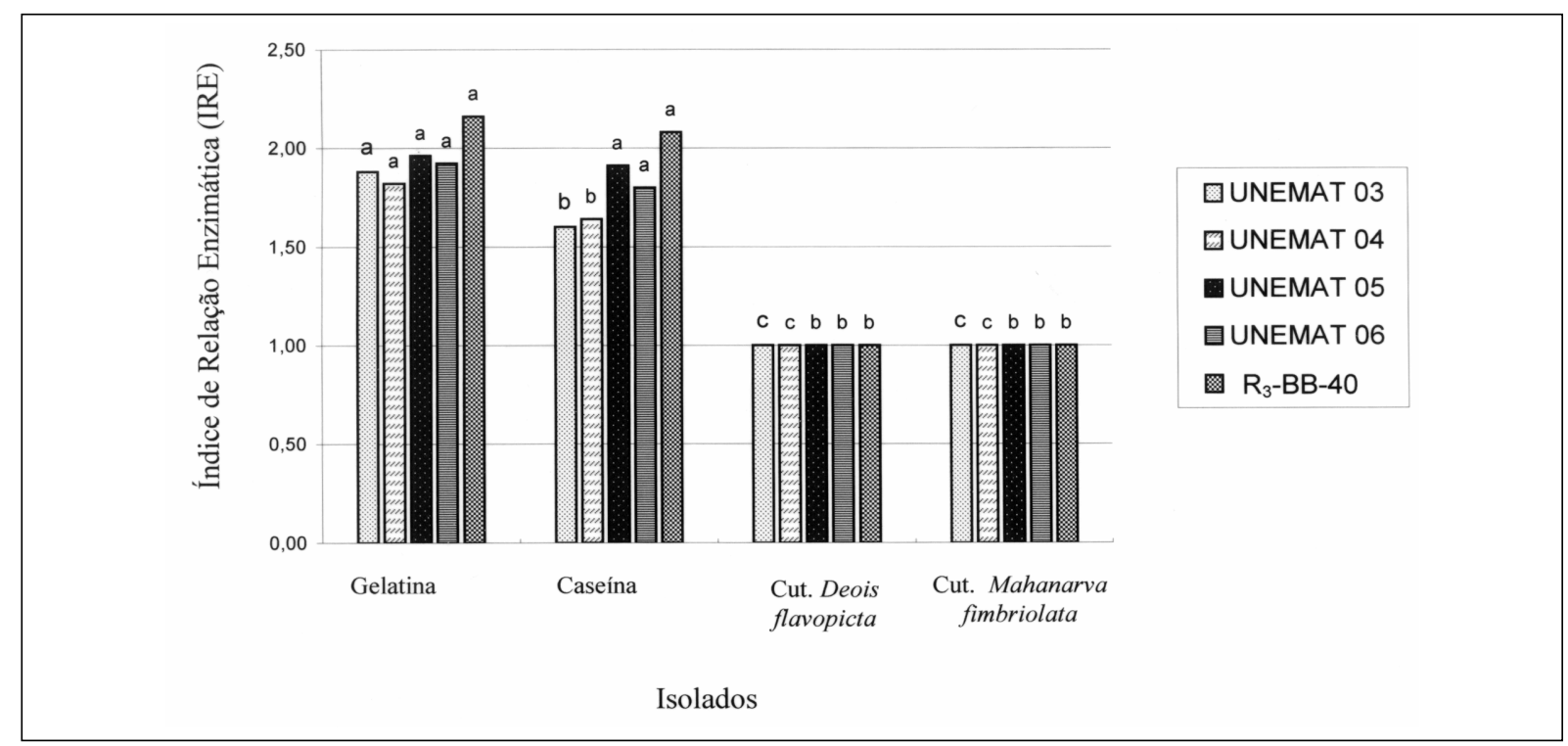

Figura 2 - Influência dos substratos cuticulares e não-cuticulares na produção de proteases extracelulares por isolados de Metarhizium anisopliae. Médias seguidas de letras iguais não diferem significativamente entre si pelo teste de Tukey a 5\% de probabilidade.

Ciência Rural, v.37, n.1, jan-fev, 2007. 


\section{REFERÊNCIAS}

ALVES, S.B. Fungos entomopatogênicos. In: ALVES, S.B. Controle microbiano de insetos. Piracicaba: FEALQ, 1998. Cap.11, p.289-381.

ALMEIDA, J.E.M. et al. Manejo integrado de pragas e doenças das culturas - pastagens. São Paulo: Secretaria de Agricultura e Abastecimento, 2000. 50p. (Manual Técnico, 2).

ANDERSEN, S.O. Cuticular sclerotization. In: MILLER, T.A. Cuticle techniques in arthropods. New York: SpringerVerlag, 1980. p.185-217.

BRAGA, G.U.L. et al. Protease production during growth and autolysis of submerged Metarhizium anisopliae cultures. Revista Microbiologia, v.30, p.107-113, 1999.

LEITE, L.G. et al. Occurrence of entomophthorales on spittlebugs pests of pasture in eastern São Paulo state, Brazil. Arquivos Instituto Biológico, São Paulo, v.69, n.3, p.63-68, 2002.

PACCOLA-MEIRELLES, L.D.; AZEVEDO, J.L. Variabilidade natural no fungo entomopatogênico Beauveria bassiana. Archives Biology Technology, v.33, n.3, p.657-672, 1990.

PATERSON, I.C. et al. Specific induction of a cuticle-degrading protease of the insect pathogenic fungus Metarhizium anisopliae. Microbiology, v.140, p.185-189, 1994.

PEREIRA, M.J.B. et al. Levantamento populacional de ninfas de Mahanarva fimbriolata cigarrinha da cana-de-açúcar (Hemiptera: Cercopidae) em Tangará da Serra, MT. In: CONGRESSO BRASILEIRO DE ENTOMOLOGIA, 20., 2004, Gramado, RS . Anais... Gramado: Sociedade Entomológica do Brasil, 2004. 694p. p.439.
PINTO, F.G.S. et al. Genetic variation in the cuticle-degrading protease activity of the entomopathogen Metarhizium flavoviride. Genetics and Molecular Biology, v.25, n.2, p.231-234, 2002.

PONTECORVO, G. et al. The genetics of Aspergillus nidulans. Advances in Genetics, v.5, p.141-238, 1953.

RIBEIRO JÚNIOR, J.I. SAEG Sistema para análises estatísticas e genética, versão 8.0. Viçosa: Fundação Arthur Bernardes, 2001. p.301.

ROSATO, Y.B. et al. Production of extracellular enzymes by isolates of Metarhizium anisopliae. Journal of Invertebrate Pathology, v.38, p.1-3, 1981.

SILVA, D. et al. Níveis populacionais de cigarrinhas das pastagens (Hemiptera: Cercopidae) em Brachiaria brizantha cv. Marandu, em Tangará da Serra, MT. In: CONGRESSO BRASILEIRO DE ENTOMOLOGIA, 20., 2004, Gramado, RS. Anais... Gramado: Sociedade Entomológica do Brasil, 2004. 694p. p.440.

SPACKI, V. et al. Estudo da produção de proteases e avaliação da compatibilidade de produtos fitossanitários apresentada pelos fungos entomopatogênicos Metarhizium anisopliae e Beauveria bassiana. In: SEMANA DE BIOLOGIA, 9., 2001, Cascavel, PR. Anais... Cascavel: Centro de Ciências Biológicas e da Saúde, 2001. 36p. p.23.

St. LEGER, R.J. et al. Regulation of production of proteolytic enzymes by the entomopathogenic fungus Metarhizium anisopliae. Archives of Microbiology, v.150, p.413-416, 1988.

TIAGO, V.P. et al. Cuticle-degrading proteases from the entomopathogen Metarhizium flavoviride and their distribution in secreted and intracellular fractions. Leters in Applied Microbiology, London, v.34, p.91-94, 2002. 